PONTES, NC; NASCIMENTO, AR; GOLYNSKI, A; MOITA, AW; MAFFIA, LA; OLIVEIRA, JR; QUEZADO-DUVAL, AM. 2017. Volume de aplicação e eficiência do controle químico da mancha bacteriana em tomateiro industrial. Horticultura Brasileira 35: 371-376. DOI - http://dx.doi.org/10.1590/ S0102-053620170309

\title{
Volume de aplicação e eficiência do controle químico da mancha bacteriana em tomateiro industrial
}

\author{
Nadson C Pontes'; Abadia R Nascimento² ${ }^{1}$ Adelmo Golynski'; Antonio W Moita ${ }^{3}$; Luiz A Maffia ${ }^{4}$; José R \\ Oliveira $^{4}$; Alice M Quezado-Duval ${ }^{3}$ \\ 1'Instituto Federal Goiano (IF Goiano), Morrinhos-GO, Brasil; nadson.pontes@ifgoiano.edu.br; adelmo.golynski@ifgoiano.edu.br;

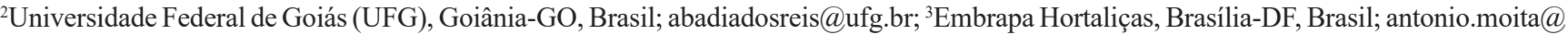 \\ embrapa.br; alice.quezado@embrapa.br; ${ }^{4}$ Universidade Federal de Viçosa (UFV), Viçosa-MG, Brasil. lamaffia@ufv.br; jrogerio@ufv.br
}

\section{RESUMO}

Foi avaliado o efeito do volume de aplicação de hidróxido de cobre (HC) e do acibenzolar-S-metil (ASM) no controle da mancha bacteriana em tomate para processamento industrial. Os ensaios foram realizados em 2010, sendo um em Brasília-DF (ensaio 1), e dois em Morrinhos-GO (ensaios 2 e 3). Os volumes empregados foram 250 e $500 \mathrm{~L} /$ ha e as aplicações realizadas semanalmente, totalizando 13 aplicações. No terceiro ensaio, o número de aplicações do ASM foi reduzido para oito e as aplicações restantes foram feitas com HC. Após as duas primeiras aplicações, as plantas foram inoculadas artificialmente com Xanthomonas perforans (ensaios 1 e 2) e $X$. gardneri (ensaio 3). Foram avaliadas, de acordo com o ensaio, a severidade da doença, a produtividade e a relação benefício/custo para cada tratamento, tendo por base o incremento de produção em relação à testemunha não tratada. Em todos os ensaios, o volume de aplicação afetou a eficiência dos produtos, com maior redução da doença com aplicação de $500 \mathrm{~L} / \mathrm{ha}$. O efeito dos tratamentos na produtividade foi variável. Com base nos resultados do terceiro ensaio, com a aplicação de ASM-HC no volume de $250 \mathrm{~L} / \mathrm{ha}$, obteve-se a maior relação benefício/custo, seguido pelo tratamento com $\mathrm{HC}$ a $500 \mathrm{~L} / \mathrm{ha}$.

Palavras-chave: Solanum lycopersicum, Xanthomonas gardneri, Xanthomonas perforans, acibenzolar-S-metil, hidróxido de cobre.

\begin{abstract}
Application volume and efficiency of bacterial spot chemical control in processing tomatoes

The aim of this study was to evaluate the effect of copper hydroxide (HC) and acibenzolar-S-methyl (ASM) volume used in spray application on the control of bacterial spot in processing tomatoes. Three trials were carried out in 2010, one in Brasília, Federal District, Brazil (trial 1), and two in Morrinhos, Goiás State, Brazil (trials 2 and 3). The volumes used were 250 and $500 \mathrm{~L} / \mathrm{ha}$ at weekly applications with a total of 13 applications. In the third trial, the number of ASM applications was reduced to eight, and the following applications were made with HC. After the second application, plants were artificially inoculated with Xanthomonas perforans (trials 1 and 2) and X. gardneri (trial 3). The variables analyzed, according to the trial, were disease severity, yield and the benefit/cost ratio. In all trials, the volume affected the products efficiency, with greater reduction of disease when applying a volume of $500 \mathrm{~L} / \mathrm{ha}$. The effect of treatments in the productivity was variable. The treatment with ASM-HC at $250 \mathrm{~L} /$ ha had the highest benefit/cost ratio, followed by the treatment with $\mathrm{HC} 500 \mathrm{~L} / \mathrm{ha}$.
\end{abstract}

Keywords: Solanum lycopersicum, Xanthomonas gardneri, Xanthomonas perforans, acibenzolar-S-methyl, copper hydroxide.

(Recebido para publicação em 22 de dezembro de 2015; aceito em 11 de outubro de 2016) (Received on December 22, 2015; accepted on October 11, 2016)

$\mathrm{N}$ o Brasil, a cultura do tomate para processamento industrial vem crescendo, resultado do aumento da demanda dos derivados de tomate (Melo \& Fonte, 2011). A produção brasileira nesse segmento concentra-se no estado de Goiás, onde as condições de clima, solo e topografia favorecem o cultivo (Silva-Junior et al., 2015). Nessa região, irrigam-se os cultivos de tomate para processamento por aspersão via pivôcentral, o que favorece a ocorrência de doenças que comprometem a produtividade e a qualidade dos frutos, com destaque para a mancha bacteriana (Quezado-Duval et al., 2004). Essa doença está associada a quatro espécies do gênero Xanthomonas: X. euvesicatoria, $X$. gardneri, $X$. perforans e $X$. vesicatoria.

Nas principais regiões produtoras do Brasil, os primeiros estudos de epidemias da mancha bacteriana em tomate para processamento indicavam a prevalência da espécie $X$. gardneri (Quezado-Duval et al., 2004). Entretanto, segundo levantamentos mais recentes, a ocorrência de $X$. perforans tem aumentado e passou a prevalecer nos campos de tomate para processamento na região central do país (Araújo et al., 2016). Essas bactérias podem sobreviver em restos culturais, sementes, plantas daninhas e plantas voluntárias (Quezado-Duval \& Lopes, 2010), o que dificulta a eliminação das fontes de inóculo. Até o momento, não há variedades comerciais desse segmento com níveis efetivos de resistência (Quezado-Duval et al., 2014). Assim, a ferramenta mais utilizada pelos produtores para o manejo da mancha bacteriana tem sido o controle químico. 
Em geral, o controle químico da doença baseia-se na aplicação de fungicidas cúpricos. O uso intensivo desses produtos pode levar ao surgimento de populações do patógeno resistentes ao cobre (Mirik et al., 2007). Segundo estudos realizados no Brasil, isolados do patógeno com resistência ao cobre ainda não são comumente detectados nas lavouras comerciais, tanto destinadas ao consumo in natura quanto ao processamento industrial (Quezado-Duval et al., 2003). Entretanto, frequentemente produtores e técnicos da cadeia do tomate para processamento relatam que a aplicação de fungicidas cúpricos não tem resultado em controle eficiente da doença. Esse fato sugere que outros fatores, que não a resistência intrínseca dos patógenos ao cobre podem estar influenciando na eficiência dos fungicidas cúpricos.

Em vista da ação apenas de contato, a aplicação de produtos à base de cobre deve proporcionar uma boa cobertura do dossel das plantas. Um dos fatores que influenciam na cobertura é o volume de calda aplicado. Produtos de contato demandam a aplicação de volume de calda maior e menor tamanho de gota, para promover maior cobertura do alvo e penetração no dossel da lavoura (Antuniassi, 2011). Porém, há uma tendência na redução do volume de calda para aplicação de produtos fitossanitários, visando reduzir os custos de produção e o uso de água, além de melhorar o rendimento do maquinário (Cullen et al., 2001; Wise et al., 2010). Nas principais regiões brasileiras de cultivo de tomate para processamento, os volumes de calda empregados têm sido continuamente reduzidos (Quezado-Duval \& Lopes, 2010). Essa redução do volume de aplicação pode diminuir a cobertura foliar e, consequentemente, a eficiência de produtos protetores com ação de contato, como os fungicidas cúpricos.

Uma outra opção que tem sido estudada visando o manejo da mancha bacteriana do tomateiro em condições de campo são os produtos indutores de resistência (Louws et al., 2001; Abbasi et al., 2002). Pode-se citar como exemplo o acibenzolar-S-Metil (benzotiadiazole, ASM) (Louws et al., 2001). Esse princípio ativo é um análogo do ácido salicílico que induz resistência sistêmica adquirida (SAR) em plantas (Durrant \& Dong, 2004).

Por ser sistêmico (Scarponi et al., 2001), o ASM poderia ser empregado em baixos volumes de calda, desde que comprovada a sua eficiência. Assim, o objetivo deste trabalho foi determinar a eficiência da aplicação do fungicida cúprico hidróxido de cobre (HC) e do ASM, em dois volumes de aplicação ( 250 e $500 \mathrm{~L} / \mathrm{ha}$ ), no controle da mancha bacteriana em tomate para processamento e no incremento da produtividade, bem como a viabilidade econômica dos tratamentos.

\section{MATERIAL E MÉTODOS}

Foram realizados três ensaios no ano de 2010. O primeiro (ensaio 1) foi conduzido no período compreendido entre 15 de março e 12 julho, na área experimental da Embrapa Hortaliças, em Brasília-DF $\left(15^{\circ} 5600^{\prime \prime S}, 48^{\circ} 08\right.$ 00"O, altitude $997 \mathrm{~m}$ ). Os outros dois ensaios foram conduzidos entre 18 de março e 16 de julho (ensaio 2), e 11 de junho e 05 de outubro (ensaio 3), na área experimental do Instituto Federal Goiano, em Morrinhos-GO (17\%49 29"S, $49^{\circ} 126^{\prime \prime}$, altitude $892 \mathrm{~m}$ ). Com base nos resultados de análise do solo obtidos antes de iniciar cada ensaio, foi realizada sua correção e adubação visando uma produtividade de $100 \mathrm{t} / \mathrm{ha}$. As mudas de tomateiro, cv. Acangatã (Heinz 9992, Heinz Seeds/Eagle Flores, Frutas \& Hortaliças), com aproximadamente 25 dias da semeadura, foram fornecidas por um viveiro comercial.

Para transplantio no campo, as mudas foram dispostas em fileiras duplas, com espaçamento de $1,10 \mathrm{~m}$ entre as duplas, $70 \mathrm{~cm}$ dentro das duplas e $37 \mathrm{~cm}$ entre plantas na fileira. A irrigação foi por aspersão via pivô-central, em regime semelhante ao utilizado em cultivos comerciais, aplicando-se lâminas de 20 $\mathrm{mm}$ no primeiro mês de cultivo, e 30 $\mathrm{mm}$ até aproximadamente 14 semanas de cultivo, quando a irrigação foi interrompida para concentrar a maturação. A parcela experimental foi composta de duas linhas paralelas (linha dupla) com espaçamento de $70 \mathrm{~cm}$ entre elas e $5 \mathrm{~m}$ de comprimento. Deixou-se um espaço de $2 \mathrm{~m}$ entre as parcelas no comprimento. Entre cada linha dupla, havia linhas simples (espaçamento de 1,10 m) utilizadas como bordaduras, de modo a prevenir eventual contaminação pela deriva dos produtos aplicados.

Os ensaios foram realizados seguindo o delineamento em blocos casualizados, em esquema fatorial $2 \times 2 \mathrm{com}$ um tratamento adicional. O primeiro fator consistiu dos produtos utilizados para o manejo da mancha bacteriana, e o segundo fator avaliado foi o volume de aplicação. $\mathrm{O}$ tratamento adicional foi uma testemunha não tratada, incluída para a detecção da possível eficiência dos tratamentos no controle da doença, bem como viabilizar a análise econômica.

Nos ensaios 1 e 2, foram avaliados os tratamentos com 13 aplicações do produto de contato HC (Kocide $\mathrm{WDG}^{\circledR}$, Du Pont do Brasil SA) em comparação à aplicação do produto sistêmico ASM (Bion ${ }^{\circledR}$, Syngenta Proteção de Cultivos Ltda.), totalizando 13 aplicações de cada produto. No terceiro ensaio, houve uma redução no número de aplicações de ASM nos tratamentos em que este era aplicado, passando de 13 para oito aplicações, sendo realizadas cinco aplicações complementares de $\mathrm{HC}$ nestes tratamentos. A redução do número de aplicações do ASM foi feita em função dos resultados obtidos no ensaio 2 , onde se observou uma redução da produtividade nos tratamentos com este produto mesmo quando houve redução da severidade da doença.

As aplicações dos produtos foram iniciadas aos sete dias após o plantio (DAP), finalizando aos 91 DAP. As concentrações de ASM e de HC foram 0,025 e 1,6 g i.a./L, respectivamente, de acordo com a recomendação constante na bula do fabricante. Para o fator "volume de aplicação" foram usados os níveis de 250 e $500 \mathrm{~L} / \mathrm{ha}$. Para a obtenção dos volumes de 250 e $500 \mathrm{~L} /$ ha nas parcelas, o aplicador percorreu toda a extensão da parcela com velocidade de 0,18 e $0,36 \mathrm{~m} / \mathrm{s}$, respectivamente. Para tanto, utilizou-se um pulverizador costal pressurizado com $\mathrm{CO}_{2}$, com pressão constante de $28 \mathrm{lbf} / \mathrm{pol}^{2}$, acoplado a uma 
barra com dois bicos do tipo leque duplo (TeeJet ${ }^{\circledR} 120 / 03$ ), com espaçamento e altura de trabalho de $50 \mathrm{~cm}$. Após 14 DAP foi efetuada a inoculação das plantas por meio da pulverização de suspensão bacteriana. Foram utilizados isolados sensíveis ao cobre das espécies $X$. perforans (EH 2009-112, ensaios 1 e 2) e X. gardneri (EH 2006-52, ensaio 3), provenientes da coleção de trabalho de bactérias fitopatogênicas da Embrapa Hortaliças. Para a inoculação, culturas bacterianas com 48 horas de incubação em meio nutriente ágar a $28^{\circ} \mathrm{C}$, foram suspensas em solução salina $(10 \mathrm{mM}$ $\mathrm{MgSO}_{4}$ ) e a sua concentração ajustada para O. . $_{600}=0,3\left(\approx 5 \times 10^{8} \mathrm{ufc} / \mathrm{mL}\right)$. A suspensão foi então diluída na razão de 1:10 e aplicada sobre as plantas ao final do dia.

Para a avaliação da severidade da doença, realizou-se uma amostragem ao acaso de 20 folíolos com sintomas ao longo da parcela para estimar a porcentagem da área foliar lesionada, por meio da escala proposta por Boff et al. (1991) nas avaliações realizadas até 60 DAP. Após esse período, em função da dificuldade em se retirar as amostras de folíolos, a severidade da doença foi determinada por atribuição de notas de severidade para a parcela inteira, com base em uma escala visual com níveis progressivos de severidade de 1 a 10 (Quezado-Duval et al., 2011). Com base nos dados de severidade, estimou-se o percentual de controle dos programas de proteção em relação à testemunha não tratada para padronizar os resultados nos diferentes ensaios, como sugerido em Roberts et al. (2008), onde: \% do controle da doença $=100 \times$ (SEVERI$\mathrm{DADE}_{\text {testemunha }}-\mathrm{SEVERIDADE} \mathrm{tratamento}_{\text {(1) }}$ ) ( SEVERIDADE testemunha ).

A colheita foi realizada nos ensaios 2 e 3 aos 120 DAP. Para estimar a produtividade ( $\mathrm{t} / \mathrm{ha}$ ), o peso total dos frutos colhidos por parcela foi dividido pelo número de plantas que compunham a parcela útil e o valor obtido multiplicado pela densidade de 30.030 plantas, calculada em função do espaçamento utilizado. Foi avaliada a viabilidade econômica dos tratamentos por meio do cálculo da relação benefício/custo. Para tal, a estimativa de ganho econômico com o incremento de produtividade em relação à testemunha não tratada foi dividida pela estimativa de custos com a aquisição dos produtos e com a aplicação no campo.

$\mathrm{O}$ valor dos custos foi acrescido de uma taxa de juros de $0,65 \%$ ao mês (média da taxa de juros real da caderneta de poupança praticada nos últimos oito anos), considerando um período de quatro meses ( 120 dias de ciclo da cultura). Assim, a relação benefício/custo (B/C) foi determinada pela fórmula:

$$
\frac{B}{C}=\sum_{t=0}^{n} \frac{B}{C(1+r)^{t}}
$$

em que B são as receitas; C, custos variáveis (aquisição dos produtos e serviço de aplicação); t, período de tempo; $\mathrm{n}$, tempo-limite (quatro meses); e r, a taxa de juros adotada. Quando B/C $>1$, o tratamento foi considerado economicamente viável. Assim como para a taxa de juros, foi levada em consideração a média dos preços da tonelada de tomate, dos produtos fitossanitários (ASM e HC), e serviços (custo da aplicação) praticados entre os anos de 2002 e 2010 (Tabela 1), fornecidos pelas empresas processadoras.

Os dados de severidade dada em percentagem de área lesionada e os dados de produtividade foram submetidos a análises de resíduos para verificar os pressupostos da ANOVA. Para atendê-los, quando necessário, os dados de percentagem de área lesionada foram transformados para $(x+0,5)^{1 / 2}$. Quando observado efeito significativo dos tratamentos sobre as referidas variáveis ( $\mathrm{F}$, $\mathrm{p} \leq 0,05)$, utilizou-se o teste de Dunnett $(p=0,05)$ para comparar os diferentes programas de aplicação em relação à testemunha não tratada. Já os dados de severidade obtidos por meio de notas (dados categóricos) foram analisados de acordo com a metodologia sugerida por Shah \& Madden (2004).

Comparando-se os tratamentos com produtos químicos e a testemunha não tratada, obteve-se o percentual de controle. Os valores desta variável, assim como os de produtividade, foram utilizados para avaliar a interação entre os fatores produto e volume de aplicação . No desdobramento, empregou-se o teste F para calcular e avaliar a significância entre os diferentes níveis de cada fator.
O efeito dos fatores sobre as variáveis estudadas foi estimado com base no p-valor. As análises foram realizadas no programa SAS 9.4 (SAS Institute, Cary, N.C., USA), utilizando-se os procedimentos, GLM, MIXED com a opção ANOVA-F para calcular a ANOVA de acordo com Shah \& Madden (2004), MEANS e RANK.

\section{RESULTADOS E DISCUSSÃO}

No ensaio 1, apenas os tratamentos com aplicação de ASM e HC em volume de aplicação de 500 L/ha proporcionaram redução significativa da severidade em relação à testemunha (Tabela 2). Quando avaliado o desdobramento da interação entre os fatores produto $\mathrm{e}$ volume de aplicação em relação ao percentual de controle, observou-se maior diferença entre os tratamentos utilizando ASM e $\mathrm{HC}$ quando aplicados a $250 \mathrm{~L} / \mathrm{ha}(\mathrm{F}, \mathrm{p}=0,07)$, do que em relação à aplicação destes a $500 \mathrm{~L} / \mathrm{ha}$ $(\mathrm{F}, \mathrm{p}=0,18)$. Quando comparados os tratamentos com diferentes volumes de aplicação para cada produto, maior diferença entre os volumes de aplicação de 250 e $500 \mathrm{~L} / \mathrm{ha}$ foi observada entre os tratamentos com $\mathrm{HC}(\mathrm{F}, \mathrm{p}=0,02)$, em relação aos tratamentos com ASM $(F, p=0,05)$. Tais resultados apontam para uma menor dependência do volume de aplicação para os tratamentos com ASM, em relação àqueles com HC.

Em relação ao ensaio 2, nas avaliações da severidade realizadas aos 72 e 91 DAP, novamente se observou diferenças em relação à testemunha apenas para os tratamentos com aplicação de $500 \mathrm{~L} / \mathrm{ha}$ de calda (Tabela 2). Quanto ao percentual de controle da doença na avaliação aos $72 \mathrm{DAP}, \mathrm{o}$ desdobramento da interação entre os fatores demonstrou haver baixo efeito dos diferentes níveis de volume de calda sobre esta variável nos tratamentos com $\operatorname{ASM}(F, p=0,10)$ e $\mathrm{HC}(F, p=0,15)$, assim como na comparação entre estes produtos nos tratamentos com $250(\mathrm{~F}$, $\mathrm{p}=0,84)$ e $500 \mathrm{~L} / \mathrm{ha}(\mathrm{F}, \mathrm{p}=0,96)$. Aos 91 DAP, foi possível observar maior diferença entre os volumes de aplicação nos tratamentos com HC (F, p= 0,03), em relação aos tratamentos com ASM $(\mathrm{F}, \mathrm{p}=0,07)$. $\mathrm{O}$ que não foi observado 
quando os produtos foram comparados entre si nos tratamentos com volumes de aplicação de $250(\mathrm{~F}, \mathrm{p}=0,42)$ e 500 $\mathrm{L} / \mathrm{ha}(\mathrm{F}, \mathrm{p}=0,80)$.

No que diz respeito aos valores de produtividade obtidos no ensaio 2 , os tratamentos com $500 \mathrm{~L} /$ ha de $\mathrm{HC}$ e 250 L/ha de ASM diferiram da testemunha (Tabela 2), tendo o primeiro porporcionado um incremento de $8 \%$ na produtividade, enquanto o segundo resultou em uma redução de 14\%. A resposta negativa dos tratamentos com ASM em relação à produtividade, mesmo quando ele proporcionou redução da severidade da doença, pode ser atribuída ao elevado número de aplicações, que, por sua vez, pode ter gerado um gasto excessivo de energia com o processo de indução de resistência. Dessa forma, no ensaio 3, nos tratamentos com ASM, o número de aplicações deste produto foi reduzido de 13 para oito, havendo a complementação do programa de manejo com cinco aplicações de HC.

No ensaio 3, quando a severidade foi avaliada por meio da estimativa da porcentagem de área foliar lesionada por folíolo, aos 60 DAP, apenas o tratamento do programa $\mathrm{HC}$ com $250 \mathrm{~L} / \mathrm{ha}$ não diferiu da testemunha (Tabela 2). Quando avaliado o efeito da interação entre os diferentes fatores sobre o percentual de controle, observou-se maior diferença entre os tratamentos ASM-HC e HC quando aplicados com volume de
$250 \mathrm{~L} / \mathrm{ha}(\mathrm{F}, \mathrm{p}=0,006)$, em comparação à aplicação destes a $500 \mathrm{~L} / \mathrm{ha}(\mathrm{F}, \mathrm{p}=$ $0,41)$. Pode-se observar que, quando os produtos foram aplicados com o menor volume de calda, houve maior percentual de controle nos tratamentos com ASM-HC. Já no desdobramento por programa, para o ASM-HC, houve menor efeito do fator volume de calda $(\mathrm{F}, \mathrm{p}=0,69)$, em relação ao observado nos tratamentos apenas com $\mathrm{HC}(\mathrm{F}, \mathrm{p}=$ $0,01)$, onde a aplicação no maior volume resultou em maior percentual de controle da mancha bacteriana. $\mathrm{Na}$ avaliação da severidade realizada aos 96 DAP, não foram observadas diferenças entre os tratamentos, em função da intensa desfolha favorecida pelo início do período chuvoso, com intensa precipitação pluviométrica entre os meses setembro e outubro (34 mm de precipitação).

Em relação à produtividade, apenas o tratamento com $\mathrm{HC}$ aplicado com volume de $250 \mathrm{~L} /$ ha não diferiu da testemunha não tratada (Tabela 2). Diferentemente do ensaio 2, ambos os tratamentos com ASM proprocionaram incremento na produtividade, o que pode ser consequência da redução do número de aplicações deste indutor de resistência. Ao se avaliar o efeito da interação dos fatores sobre o incremento da produtividade, no desdobramento da interação por volume, a maior diferença entre os programas de aplicação com ASM-HC e $\mathrm{HC}$ foi observada nos tratamentos

Tabela 1. Relação benefício/custo (B/C) em função do incremento de produtividade obtido pelos tratamentos do ensaio 3, em relação à testemunha não tratada: HC (hidróxido de cobre em 13 aplicações semanais) e ASM-HC ( 8 de acibenzolar-S-metil seguidas de 5 de hidróxido de cobre) em dois volumes de aplicação (250 e $500 \mathrm{~L} / \mathrm{ha}$ ), e do custo de cada tratamento $\{$ benefit/cost ratio $(\mathrm{B} / \mathrm{C})$ due to the productivity increase obtained by treatments of the trial 3 , by comparison to the untreated control: HC (weekly applications of copper hydroxide) and ASM-HC ( 8 of acibenzolar-S-methyl followed copper hydroxide) using two spray volumes (250 e $500 \mathrm{~L} / \mathrm{ha})$, and the cost of each treatment $\}$. Morrinhos, IF Goiano, 2010.

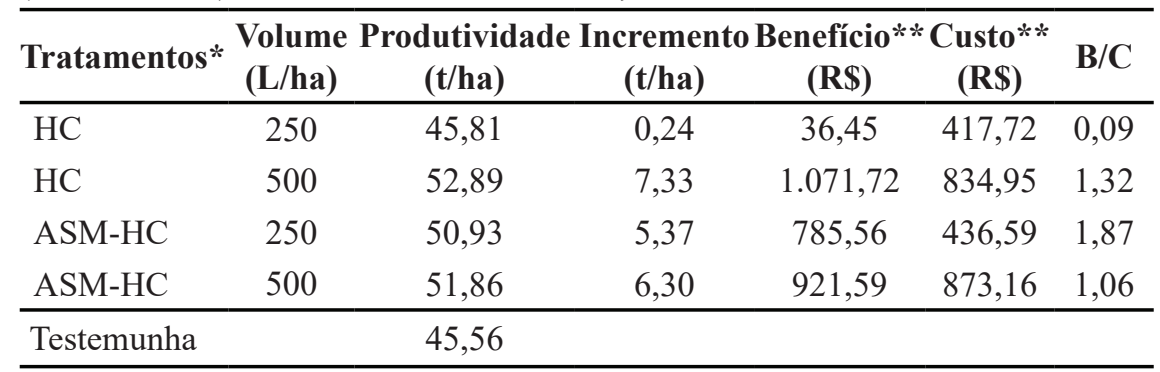

*Doses: ASM, 0,025 g i.a./L (ASM, 0,025 g a.i/L) and HC, 1,6 g i.a./L (HC, 1,6 g a.i./L). **Preços médios aplicados nos últimos oito anos: tomate ( $\$$ 146,20/t), hidróxido de cobre ( $\mathrm{R} \$ 0,016 / \mathrm{g}$ produto comercial), acibenzolar-S-metil ( $\mathrm{R} \$ 1,18 / \mathrm{g}$ produto comercial), custo de aplicação ( $\mathrm{R} \$ 33,33 / \mathrm{ha}$ ) \{average prices applied in the past eight years: Tomato ( $\mathrm{R} \$$ 146.20/t), copper hydroxide (R \$ 0.016/g commercial product), acibenzolar-S-methyl (R\$ $1.18 /$ g commercial product), cost application ( $\mathrm{R} \$ 33.33 / \mathrm{ha})\}$ com volume de aplicação de $250 \mathrm{~L} / \mathrm{ha}$ $(\mathrm{F}, \mathrm{p}=0,05)$, em relação à comparação dos programas nos tratamentos com 500 $\mathrm{L} / \mathrm{ha}(\mathrm{F}, \mathrm{p}=0,66)$. Quando aplicados a $250 \mathrm{~L} / \mathrm{ha}$, o tratamento com ASM-HC proporcionou um incremento de $11 \%$ na produtividade em relação à testemunha. Esse incremento foi similiar ao tratamento em que esta combinação foi aplicada com $500 \mathrm{~L} / \mathrm{ha}(\mathrm{F}, \mathrm{p}=0,69)$, o qual resultou em incremento de $12 \%$ na produtividade. $\mathrm{O}$ mesmo não aconteceu em relação aos tratamentos com $\mathrm{HC}$, onde houve maior diferença entre os tratamentos com os diferentes volumes de calda avaliados ( $F, p=0,01)$.

A redução da produtividade ocasionada pela utilização do ASM tem sido observada em vários estudos (Louws et al., 2001; Abbasi et al., 2002). Sabe-se que, associado à indução de resistência, existe um custo energético pela realocação de metabólitos e energia de outros processos, como crescimento e reprodução, para a defesa (Durrant \& Dong, 2004; Walters \& Fountaine, 2009). Além do gasto energético, o ASM pode ser fitotóxico quando aplicado em concentrações elevadas, com consequente redução da produtividade (Abbasi et al., 2002; Huang et al., 2012). No entanto, a questão do número de aplicações pode ser a causa da redução de produtividade e não do volume de aplicação, já que no ensaio 2, apesar de o ASM ter sido aplicado em menor volume, não se teve incremento em produtividade (redução de $14 \%$ em relação ao controle), nem diferenças significativas entre os dois volumes testados. Os trabalhos de Roberts et al. (2008) e Huang et al. (2012), onde só foi possível observar efeito do ASM na redução da severidade da mancha bacteriana com número de aplicações inferiores a 10 (recomendação contida na bula do produto), corroboram para essa hipótese.

Como apenas no terceito ensaio foi possível ajustar um número de aplicações do ASM, de modo a não comprometer a produtividade, os dados referentes a este ensaio foram utilizados para o cálculo da relação benefício/custo. Dentre os tratamentos avaliados, apenas HC, com um volume de aplicação de $250 \mathrm{~L} /$ ha não resultou em um incremento de produção que recompensasse os custos de aplicação 
(Tabela 1). Os maiores valores foram observados para os tratamentos com $\operatorname{ASM}(250 \mathrm{~L} / \mathrm{ha})$ e HC (500 L/ha), que proporcionaram uma relação benefício/ custo de 1,87 e 1,32, respectivamente.

Para o programa de aplicação apenas com hidróxido de cobre semanal, ficou evidente a dependência da eficiência do produto em relação ao volume de calda aplicado. Em relação ao ASM, a influência do volume de aplicação sobre o controle da mancha bacteriana foi menor, o que foi evidenciado nos desdobramentos da interação por programa em quatro das cinco avaliações de percentual de controle, ainda que se tenha observado efeito mais pronunciado sobre o controle da doença e incremento da produtividade com aplicações de $500 \mathrm{~L} / \mathrm{ha}$. Tal fato corrobora a ideia de que fungicidas cúpricos, por serem produtos de contato, demandam maiores volumes de aplicação em relação a produtos sistêmicos, pois necessitam de maior cobertura da área foliar para alcançar sua eficiência (Wise et al., 2010). Desse modo, a redução do volume de aplicação não deve ser feita sem critério, sob pena de ocorrer perca de eficiência em controle e consequente redução ou até perca de ganho econômico. A situação desejável, seria que a recomendação fosse mais detalhada, com base em curvas de eficiência em função da cobertura foliar, dada a dosagem em i.a./L recomendada.

No presente estudo, a concentração do produto comercial foi constante (equivalente a $0,025 \mathrm{~g}$ i.a./L), independente do volume utilizado, seguindo as recomedações da bula. Assim, a quantidade de ASM distribuída por área foi de 12,5 e $6,25 \mathrm{~g}$ i.a./ha para os volumes de 500 e $250 \mathrm{~L} / \mathrm{ha}$, respectivamente. Huang et al. (2012) estimaram uma concentração ideal de ASM de $0,03 \mathrm{~g}$ i.a./L para a melhor eficiência no controle da mancha bacteriana, um pouco superior ao recomendado no produto comercial disponibilizado no Brasil. Como no trabalho citado o volume de aplicação variou entre 559 e $1.121 \mathrm{~L} / \mathrm{ha}$, a quantidade de ASM aplicada por área, considerando a concentração ideal $(0,03$ g i.a./L), estaria entre 16,77 e 33,63 g/ha. Além disso, esses níveis estariam dentro das quantidades que não provocariam fitotoxidez, já que existem relatos de fitotoxidez em tomate provocada por ASM quando aplicado em quantidades próximas de $35 \mathrm{~g}$ i.a./ha (Abbasi et al., 2002).

O tratamento com a aplicação de $500 \mathrm{~L} / \mathrm{ha}$, foi o que mais se aproximou das quantidades reportadas. Aplicações de ASM com volumes de calda inferiores ao ponto de escorrimento, mas que mantivessem a dose de $12,5 \mathrm{~g}$ i.a./ha, poderiam garantir a eficiência do pro- duto. Ressalta-se ainda que os valores de volume de aplicação utilizados por Huang et al. (2012) corresponderam a aplicações em tomateiro tutorado, que possivelmente demandam volumes maiores (800 a $1000 \mathrm{~L} / \mathrm{ha}$, de acordo com a bula do produto comercial) que os aplicados em cultivo rasteiro para a obtenção da cobertura foliar pelo produto.

Em culturas com a formação de grande massa foliar, como no cultivo rasteiro do tomateiro, a obtenção de boa cobertura foliar pela aplicação de produtos fitossanitários torna-se ainda mais difícil. Cullen et al. (2001) obtiveram valores de cobertura foliar inferiores a $2 \%$ no interior do dossel de parcelas de tomate para processamento pulverizados com volume de aplicação de 283 e $568 \mathrm{~L} / \mathrm{ha}$. O menor depósito de produtos de contato no interior do dossel torna-se mais preocupante, em função de ser essa a região com microclima mais favorável ao desenvolvimento de fitopatógenos. O aumento do volume de aplicação pode aumentar a deposição dos produtos pulverizados no interior do dossel. Em feijoeiro, cultura também com grande massa foliar, Limberger (2006) observou aumento no depósito de fungicidas nos extratos médios e inferiores do dossel com o aumento do volume de calda aplicado.

Tabela 2. Severidade da mancha bacteriana (SEV) e produtividade (PROD) obtidas pelos tratamentos com aplicação de 250 e 500 L/ha de acibenzolar-S-metil (ASM) ou integrado ao hidróxido de cobre (ASM-HC), de acordo com o ensaio, e hidróxido de cobre (HC) \{severity of bacterial spot (SEV) and yield (PROD) obtained by treatments with application of 250 and $500 \mathrm{~L} / \mathrm{ha}$ of acibenzolar-S-methyl (ASM) or integrated with copper hidroxide, according to the trial (ASM-HC) and copper hydroxide (HC) \}. Morrinhos, IF Goiano, 2010.. Morrinhos, IF Goiano, 2010.

\begin{tabular}{|c|c|c|c|c|c|c|c|}
\hline \multirow{2}{*}{ Tratamentos } & \multirow{2}{*}{$\begin{array}{c}{\text { Ensaio } 1^{1}}^{\text {SEV } 56} \\
\end{array}$} & \multicolumn{3}{|c|}{ Ensaio $2^{1}$} & \multicolumn{3}{|c|}{ Ensaio $3^{2}$} \\
\hline & & SEV 72 & SEV 91 & PROD & SEV 60 & SEV 96 & PROD \\
\hline $\mathrm{ASM}^{1} / \mathrm{ASM}-\mathrm{HC}^{2} 250 \mathrm{~L} / \mathrm{ha}$ & 22,37 & 3,22 & 4,43 & $103,37^{*}$ & $24,65^{*}$ & $4,62^{\mathrm{NS}}$ & $50,93 *$ \\
\hline $\mathrm{ASM}^{1} / \mathrm{ASM}-\mathrm{HC}^{2} 500 \mathrm{~L} / \mathrm{ha}$ & $20,14^{*}$ & $2,78^{* *}$ & $3,82 * *$ & 112,43 & $23,07 *$ & 4,00 & $51,86^{*}$ \\
\hline $\mathrm{HC}^{3} 250 \mathrm{~L} / \mathrm{ha}$ & 24,55 & 3,17 & 4,67 & 112,68 & 31,74 & 4,50 & 45,81 \\
\hline $\mathrm{HC}^{3} 500 \mathrm{~L} / \mathrm{ha}$ & $21,56^{*}$ & $2,80 * *$ & $3,90 * *$ & $128,12 *$ & $24,69 *$ & 4,00 & $52,89 *$ \\
\hline Testemunha & 24,79 & 3,62 & 4,92 & 117,17 & 33,81 & 4,62 & 45,56 \\
\hline CV $(\%)$ & 3,0 & 9,60 & 12,20 & 6,14 & 9,08 & 13,16 & 5,66 \\
\hline
\end{tabular}

${ }^{1} 13$ aplicações semanais de ASM, nos ensaios 1 e 2 (13 weekly applications of ASM in trials 1 and 2). ${ }^{2} 8$ aplicações de ASM seguidas de 5 de HC no ensaio 3 ( 8 weekly applications of ASM followed by 5 of HC, in trial 3 ); ${ }^{3} 13$ aplicações semanais de HC (13 weekly applications of $\mathrm{HC}$ ), nos ensaios 1,2 e $3 .{ }^{*}$ Difere da testemunha não tratada pelo teste de Dunnett $(\mathrm{p} \leq 0,05)$ \{significantly different from the control by Dunnett test $(\mathrm{p} \leq 0.05)\}{ }^{* *}$ Difere da testemunha não tratada, considerando o intervalo de confiança $\left.61 \alpha=0,05\right)$ do efeito relativo dos tratamentos, calculados em acordo ao sugerido por Shah \& Madden (2004) \{Averages significantly different from the control, considering the confidence interval $(\alpha=0.05)$ of the treatment relative effect, calculated according to suggested by Shah \& Madden (2004) $\}$; NSNão significativo (not significant); Doses: ASM, 0,025 g i.a./L (ASM, 0,025 g a.i/L) and HC, 1,6 g i.a./L (HC, 1,6 g a.i./L). Os números que se seguem à severidade (SEV) correspondem ao período da avaliação em dias após o plantio (Numbers following the seveirity (SEV) correspond to the evaluation period in days after planting); SEV 56 e SEV 60: \% de área foliar lesionada em 20 folíolos/parcela (\% of necrotic area per 20-leaflet per plot); demais avaliações foram baseadas em uma escala de notas progressiva de 1 a 10 (Quezado-Duval et al., 2011) \{other evaluations were based on a scale of disease levels from 1 to 10$\}$ 
Por outro lado, o aumento do volume de calda pulverizado pode resultar em aumento do risco de contaminação do solo, em função do escorrimento do produto que não fica retido nas folhas (Limberger, 2006). Esse perigo é maior com fungicidas cúpricos, tendo em vista os problemas que o acúmulo de cobre no solo pode causar ao meio ambiente (Bernard et al., 2009; Komárek et al., 2010). Assim, outras medidas devem ser adotadas para aumentar a eficiência de cobertura foliar para fungicidas cúpricos, sem que seja necessário um aumento na quantidade de cobre aplicada. Pontas de pulverização que geram gotas mais finas possibilitam maior penetração do dossel (Cullen et al., 2001). Entretanto, gotas menores também são mais suscetíveis à deriva (Limberger, 2006). Uma forma de aumentar a deposição de produtos pulverizados no interior do dossel é a adoção de novas técnicas de aplicação, como a aplicação assistida por ar, eficiente em aumentar a penetração no dossel de outras culturas adensadas, como a soja, mas reduzindo o risco de deriva (Derksen et al., 2008), e a pulverização eletrostática (Chaim \& Wadt, 2015).

Tendo em vista a influência do volume de aplicação sobre a eficiência dos produtos avaliados no controle da mancha bacteriana do tomateiro em cultivos destinado ao processamento industrial, o ASM poderia ser utilizado nas primeiras semanas de cultivo, quando são empregados volumes de calda menores. Considerando-se que o volume de aplicação deve ser adequado ao estádio de crescimento da planta, sendo crescente ao longo do desenvolvimento da cultura, produtos com ação de contao seriam empregados a partir do momento em que o volume de aplicação fosse adequado para a sua maior eficiência, como no caso dos fungicidas cúpricos.

\section{REFERÊNCIAS}

ABBASI, PA; SOLTANI, N; CUPPELS, DA; LAZAROVITS, G. 2002. Reduction of bacterial spot disease severity on tomato and pepper plants with foliar applications of ammonium lignosulfonate and potassium phosphate. Plant Disease 86: 1232-1236.

ANTUNIASSI, UR. 2011. Tecnologia de aplicação de fungicidas para culturas anuais. Tropical
Plant Pathology 36 (Supplement):1329-1332. ARAÚJO, ER; COSTA, JR; FERREIRA, MASV; QUEZADO-DUVAL, AM. 2016. Widespread distribution of Xanthomonas perforans and limited presence of $X$. gardneri in Brazil. Plant Pathology (Early View DOI: 10.1111/ ppa.12543 ): 1:10.

BERNARD, L; MARON, PA; MOUGEL, C; NOWAK, V; LÉVÊQUE, J; MAROL, C; BALESDENT, J; GIBIAT, F; RANJARD, L. 2009. Contamination of soil by copper affects the dynamics, diversity, and activity of soil bacterial communities involved in wheat decomposition and carbon storage. Applied and Environmental Microbiology 75 : 7565-7569.

BOFF, P; ZAMBOLIM, L; RIBEIRO DO VALE, FX. 1991. Escalas para avaliação de severidade da mancha-de-estenfílio (Stemphylium solani) e da pinta-preta (Alternaria solani) em tomateiro. Fitopatologia Brasileira 16: 280-283.

CHAIM, A; WADT, LGR. 2015, 01 de abril. Pulverização eletrostática: a revolução na aplicação de agrotóxicos. Disponível em: https://www.embrapa.br/busca-de-noticias/-/ noticia/2615385/artigo---pulverizacaoeletrostatica-a-revolucao-na-aplicacao-deagrotoxicos. Acessado em 06 de outubro de 2016.

CULLEN, E; ZALOM, F; STEINKE, W; HUMMEL, N. 2001. High-volume applications to improve canopy penetration and efficacy of reduced risk insecticides in processing tomatoes. Acta Horticulture 542: 31-37.

DERKSEN, RC; ZHU, H; OZKAN, HE; HAMMOND, RB; DORRANCE, AE; SPONGBERG, AL. 2008. Determining the influence of spray quality, nozzle type, spray volume, and air-assisted application strategies on deposition of pesticides in soybean canopy. Transactions of the ASABE 51: 1529-1537.

DURRANT, WE; DONG, X. 2004. Systemic acquired resistance. Annual Review of Phytopathology 42: 185-209.

HUANG, CH; VALLAD, GE; ZHANG, S; WEN, A; BALOGH, B; FIGUEIREDO, JFL; BEHLAU, F; JONES, JB; MOMOL, MT; OLSON, SM. 2012. Effect of application frequency and reduced rates of acibenzolarS-methyl on the field efficacy of induced resistance against bacterial spot on tomato. Plant Disease 96: 221-227.

KOMÁREK, M; ČADKOVÁ, E; CHRASTNÝ, V; BORDAS, F; BOLLINGER, JC. 2010. Contamination of vineyard soils with fungicides: a review of environmental and toxicological aspects. Environment International 36: 138-151.

LIMBERGER, AR. 2006. Avaliação da deposição da calda de pulverização em função do tipo de ponta e do volume aplicado, na cultura do feijão. Marechal Cândido Rondon: UNIOESTE. 51p. (Dissertação mestrado).

LOUWS, FJ; WILSON, M; CAMPBELL, HL; CUPPELS, DA; JONES, JB; SHOEMAKER, PB; SAHIN, F; MILLER, SA. 2001. Field control of bacterial spot and bacterial speck of tomato using a plant activator. Plant Disease 85: 481-488.

MELO ,PCT; FONTE, LC. 2011. Brazil processing tomato season 2010: results and future perspectives. Tomato News 3: 15-19.

MIRIK, M; AYSAN, Y; CINAR, O. 2007. Copperresistance strains of Xanthomonas axonopodis pv. vesicatoria (Doidge) Dye in the eastern Mediterranean region of Turkey. Journal of Plant Pathology 89: 153-154.

QUEZADO-DUVAL, AM; GAZZOTO FILHO, A; LEITE JUNIOR, RP; CAMARGO, LEA. 2003. Sensibilidade a cobre, estreptomicina e oxitetraciclina em Xanthomonas spp. associadas à mancha-bacteriana do tomate para processamento industrial. Horticultura Brasileira 21: 670-675.

QUEZADO-DUVAL, AM; LEITE, RP; TRUFFI, D; CAMARGO, LEA. 2004. Outbreaks of bacterial spot caused by Xanthomonas gardneri on processing tomato in Central-West Brazil. Plant Disease 88: 157-161.

QUEZADO-DUVAL, AM; LOPES, CA. 2010. Mancha-bacteriana: uma atualização para o sistema de produção integrada de tomate indústria. Circular Técnica (Embrapa Hortaliças) 84: 1-24.

QUEZADO-DUVAL, AM; NASCIMENTO, AR; PONTES, NC; MOITA, AW; ASSUNÇÃO, A; GOLYNSKI, A; INOUE-NAGATA, AK; OLIVEIRA, RT; CASTRO, YO; MELO, BJ. 2014. Desempenho de híbridos de tomate para processamento industrial em pressão de begomovirose e de mancha-bacteriana. Horticultura Brasileira 32: 446-45.

QUEZADO-DUVAL, AM; PONTES, NC; NASCIMENTO, AR; MOITA, AW. 2011. Metodologia de avaliação da severidade da mancha bacteriana em tomateiro para processamento industrial. Brasília: Embrapa. 24p. (Boletim de Pesquisa e Desenvolvimento 73).

ROBERTS, PD; MOMOL, MT; RITCHIE, L; OLSON, SM; JONES, JB; BALOGH, B. 2008. Evaluation of spray programs containing famoxadone plus cymoxanil, acibenzolarS-methyl, and Bacillus subtilis compared to copper sprays for management of bacterial spot on tomato. Crop Protection 27: 1519-1526.

SCARPONI, L; BUONAURIO, R; MARTINETTI, L. 2001. Persistence and translocation of a benzothiadiazole derivative in tomato plants in relation to systemic acquired resistance against Pseudomonas syringae pv. tomato. Pest Management Science 57: 262-268.

SHAH, DA; MADDEN, LV. 2004. Nonparametric analysis of ordinal data in designed factorial experiments. Phytopathology 94: 33-43.

SILVA-JUNIOR, AR; RIBEIRO, WM; NASCIMENTO ,AR; SOUZA, CB. 2015. Cultivo do tomate industrial no estado de Goiás: evolução das áreas de plantio e produção. Conjuntura Econômica Goiana 34: 97-109.

WALTERS, DR; FOUNTAINE, JM. 2009. Practical application of induced resistance to plant diseases: an appraisal of effectiveness under field conditions. Journal of Agricultural Science 147: 523-535.

WISE, JC; JENKINS, PE; SCHILDER, AMC; VANDERVOORT, C; ISAACS, R. 2010. Sprayer type and water volume influence pesticide deposition and control of insect pests and diseases in juice grapes. Crop Protection 29: $378-385$ 